\title{
Thermosensory threshold: a sensitive test of HIV associated peripheral neuropathy?
}

\author{
Mia Huengsberg ${ }^{1}$, John B Winer ${ }^{2}$, Jonathan DC Ross ${ }^{1}$ and Mohsen Shahmanesh ${ }^{1}$ \\ ${ }^{1}$ Department of GU Medicine and ${ }^{2}$ Department of Neurology, University Hospital Birmingham NHS Trust, West \\ Midlands, UK
}

\begin{abstract}
The purpose of the study was to assess the prevalence of thermosensory abnormalities in patients infected with HIV infection. Using a Thermo Sensory Analyser, we assessed thermosensory threshold for warm sensation (WS) and cold sensation (CS) of the forearm and foot in 40 controls and 75 HIV positive patients, including five patients with clinically evident peripheral neuropathy, three with AIDS-related dementia and 20 with AIDS. We found that thermosensory threshold is a reproducible test. The 95th centile for normal WS of the forearm was $1.4^{\circ} \mathrm{C}$ above and CS $0.9 \mathrm{C}$ below the baseline temperature of $32^{\circ} \mathrm{C}$, and for WS of the foot was $5.3^{\circ} \mathrm{C}$ and CS $4.4^{\circ} \mathrm{C}$ respectively. The median WS of the foot for controls was 1.4 (IQR $0.7-2.8){ }^{\circ} \mathrm{C}$, for asymptomatic HIV positive patients was $1.9(1.1-4.2){ }^{\circ} \mathrm{C}$, for patients with AIDS was $3.5(1.6-5.7)$ ${ }^{\circ} \mathrm{C}$ and for those with peripheral neuropathy was $5.4(1.7-14.9){ }^{\circ} \mathrm{C}(P<0.05$ compared to controls). A higher threshold was also evident for CS in patients with advanced HIV disease. These findings suggest that thermosensory testing is a sensitive tool in detecting early, small nerve fibre disease before the onset of clinically evident peripheral neuropathy.
\end{abstract}

Keywords: HIV; peripheral neuropathy; temperature sense; sensory thresholds

\section{Introduction}

Peripheral nerve disease is a common neurological problem in patients infected with human immunodeficiency virus (HIV). Reported prevalence varies from $10-50 \%$ (Dalakas and Pezeshkpour, 1988; Fuller et al, 1993) with an upward temporal trend in annual incidence rate (Bacellar et al, 1994). An even higher proportion of patients dying with AIDS had demonstrable histological abnormalities of their peripheral nerves (de la Monte et al, 1988; Fuller et al, 1990).

Large nerve fibres conduct nerve impulses more rapidly and their deficits can best be quantified by electromyography and nerve conduction studies. However, temperature sensation is mediated by small nerve fibres (Light and Perl, 1984) and examination of thresholds for temperature perception can provide evidence of small-fibre neuropathy

Correspondence: Dr M Huengsberg, Department of GU Medicine, Whittall Street Clinic, Birmingham B4 6DH, UK.

Received 24 November 1997; revised 12 January 1998; accepted 18 February 1998
(Dyck et al, 1984; Fruhstorfer et al, 1976). Clinically, the most common HIV related neuropathy is distal, symmetrical and predominantly sensory (Winer et al, 1992; Fuller et al, 1993), sharing similarities with diabetic neuropathy (Brown and Asbury, 1984). Small-fibre neuropathy can occur in both conditions, as evident by abnormalities of thermal sensitivity (Smith et al, 1990; Winer et al, 1992; Navarro and Kennedy, 1991; Claus et al, 1993) as well as pathological studies, where unmyelinated axon density was found to be low in patients with diabetes (Brown et al, 1976; Said et al, 1983), and in those with AIDS (Fuller et al, 1991). We set out to assess the prevalence of thermosensory abnormalities in patients infected with HIV infection.

\section{Results}

The 95th centile of the warm sensation (WS) of the forearm of normal controls was $2.4^{\circ} \mathrm{C}$ above, and of the cold sensation (CS) was $1.6^{\circ} \mathrm{C}$ below the baseline temperature of $32^{\circ} \mathrm{C}$. The 95th centile of 
the warm sensation (WS) of the foot was $5.9^{\circ} \mathrm{C}$ above, and of the cold sensation (CS) was $3.9^{\circ} \mathrm{C}$ below the baseline temperature, and these were taken as the upper limits of normal.

The co-efficient of variability (CV) of the mean of the WS and CS of the forearm were $24 \%$ and $21 \%$ and of the foot were $24 \%$ and $33 \%$ respectively.

Forty-seven of the 75 HIV positive subjects (62\%) were asymptomatic and $28(36 \%)$ had had at least one AIDS-defining illness prior to or within 30 days of their thermosensory tests. This included three patients with clinically evident peripheral neuropathy (PN), three with AIDS-Related Dementia (ARD) and two with both.

The results for WS and CS of the foot and forearm of the HIV negative controls, asymptomatic HIV positive patients, patients who developed their first AIDS defining events excluding neurological abnormalities, and patients who developed PN and/or ARD are summarised in Table 1.

The median CD4 cell count of the HIV positive subjects was $250 / \mathrm{mm}^{3}$ (inter-quartile range $110-$ $340 / \mathrm{mm}^{3}$ ). The relationship of thermosensory thresholds to patients' CD4 counts is shown in Table 2.

Five patients had clinically evident peripheral neuropathy with symptoms mainly involving the feet, and one also had numbness of the fingers. All had abnormal WS and/or CS of the foot, and one had abnormal thermosensory thresholds of the forearm (see Table 3). One additional patient with asymptomatic HIV disease but a history of cerebral vascular accident had abnormal symptom and disability scores but normal thermosensory thresholds.

Forty-seven patients $(63 \%)$ took zidovudine, 15 $(20 \%)$ took didanosine (ddI) or zalcitabine (ddC) either alone or in combination with zidovudine, and four patients took dapsone. Thermosensory threshold data of those who did and did not take ddI or ddC are presented in Table 4. Patients with PN/ ARD were excluded from this analysis, and the
Table 2 Relationship between thermosensory threshold to CD4 count (above baseline temperature of $32^{\circ} \mathrm{C}$ )

\begin{tabular}{|c|c|c|c|c|c|}
\hline \multirow{2}{*}{$\begin{array}{l}C D 4 \\
\left(\text { per } \mathrm{mm}^{3}\right)\end{array}$} & \multirow[b]{2}{*}{ Tests } & \multicolumn{2}{|c|}{$\begin{array}{c}\text { Hand } \\
\text { Inter- } \\
\text { quartile }\end{array}$} & \multicolumn{2}{|c|}{$\begin{array}{c}\text { Foot } \\
\text { Inter- } \\
\text { quartile }\end{array}$} \\
\hline & & Median & range & Median & range \\
\hline$>200$ & WS & 0.9 & $0.6-1.4$ & 2.1 & $1.1-4.8$ \\
\hline$n=34$ & CS & 0.6 & $0.4-1.4$ & 1.4 & $0.9-3.1$ \\
\hline$<200$ & WS & 0.8 & $0.4-1.4$ & 2.35 & $1.4-5.1$ \\
\hline$n=30$ & CS & 0.6 & $0.4-0.9$ & $2.4^{*}$ & $1.4-4.2$ \\
\hline
\end{tabular}

${ }^{*} P<0.05$ (Mann - Whitney U test)

Table 3 Thermosensory thresholds of patients with clinically evident peripheral neuropathy (above or below baseline temperature of $32^{\circ} \mathrm{C}$ )

\begin{tabular}{lcccc}
\hline $\begin{array}{l}\text { Patient } \\
\text { number }\end{array}$ & $\begin{array}{c}\text { Hand WS } \\
\text { (normal } \\
\leqslant 2.4)\end{array}$ & $\begin{array}{c}\text { Hand CS } \\
\text { (normal } \\
\leqslant 1.6)\end{array}$ & $\begin{array}{c}\text { Foot WS } \\
\text { (normal } \\
\leqslant 5.9)\end{array}$ & $\begin{array}{c}\text { Foot CS } \\
\text { (normal } \\
\leqslant 3.9)\end{array}$ \\
\hline I & 0.6 & 0.6 & 5.4 & $5.4^{*}$ \\
II & 3.1 & 0.1 & 1.8 & $5.4^{*}$ \\
III & $3.9^{*}$ & 1.4 & $21.9^{*}$ & $7.9^{*}$ \\
IV & 1.5 & 1.4 & 1.6 & $4.5^{*}$ \\
V & 1.6 & 1.9 & $7.9^{*}$ & $20.0^{*}$ \\
\hline
\end{tabular}

*Abnormal thresholds (defined as the 95th centile of normal controls)

Table 4 Effect of ddI/ddC on thermosensory thresholds. Median and inter-quartile range (in brackets)

\begin{tabular}{|c|c|c|c|c|c|}
\hline & $C D 4$ & $\begin{array}{c}\text { Hand WS } \\
{ }^{\circ} \mathrm{C}\end{array}$ & $\begin{array}{c}\text { Hand } C S \\
{ }^{\circ} \mathrm{C}\end{array}$ & $\begin{array}{c}\text { Foot WS } \\
{ }^{\circ} \mathrm{C}\end{array}$ & $\begin{array}{c}\text { Foot } C S \\
{ }^{\circ} \mathrm{C}\end{array}$ \\
\hline $\begin{array}{r}\mathrm{ddI} / \mathrm{ddC} \\
(n=13)\end{array}$ & $\begin{array}{c}170 \\
(40-250)\end{array}$ & $\begin{array}{c}0.6 \\
(0.4-1.1)\end{array}$ & $\begin{array}{c}0.6 \\
(0.5-1.7)\end{array}$ & $\begin{array}{c}3.4 \\
(1.1-4.8)\end{array}$ & $\begin{array}{c}1.9 \\
(1.1-3.5)\end{array}$ \\
\hline $\begin{array}{l}\text { No ddI/ddC } \\
(n=27)\end{array}$ & $\begin{array}{c}155 \\
(95-262)\end{array}$ & $\begin{array}{c}0.6 \\
(0.5-1.0)\end{array}$ & $\begin{array}{c}0.5 \\
(0.4-0.9)\end{array}$ & $\begin{array}{c}2.1 \\
(1.4-5.1)\end{array}$ & $\begin{array}{c}1.6 \\
(1.1-3.1)\end{array}$ \\
\hline
\end{tabular}

$P=$ NS (Mann-Whitney U test)

Table 1 Thermosensory thresholds for warm and cold sensation (above or below baseline temperature of $32^{\circ} \mathrm{C}$ )

\begin{tabular}{|c|c|c|c|c|c|c|c|}
\hline Groups & Tests & Median & $\begin{array}{c}\text { Hand } \\
\text { Inter-quartile } \\
\text { range }\end{array}$ & $\mathrm{P}$ value & Median & $\begin{array}{c}\text { Foot } \\
\text { Inter-quartile } \\
\text { range }\end{array}$ & $\mathrm{P}$ value \\
\hline \multirow{2}{*}{$\begin{array}{r}\text { Controls } \\
(n=40)\end{array}$} & WS & 0.6 & $0.6-1.1$ & - & 1.4 & $0.7-2.8$ & - \\
\hline & CS & 0.6 & $0.6-1.1$ & - & 1.1 & $0.9-3.1$ & - \\
\hline \multirow{2}{*}{$\begin{array}{l}\text { Asymptomatic } \\
(n=47)\end{array}$} & WS & 0.8 & $0.6-1.3$ & 0.08 & 1.9 & $1.1-4.2$ & 0.02 \\
\hline & CS & 0.8 & $0.6-1.1$ & 0.36 & 1.8 & $0.9-3.1$ & 0.35 \\
\hline \multirow{2}{*}{$\begin{array}{l}\text { AIDS } \\
\quad(n=20)\end{array}$} & WS & 1.0 & $0.6-2.0$ & 0.07 & 3.5 & $1.6-5.7$ & 0.005 \\
\hline & CS & 0.6 & $0.4-1.2$ & 0.67 & 2.7 & $1.4-3.5$ & 0.04 \\
\hline \multirow{2}{*}{$\underset{(n=5)}{\mathrm{PN} \pm \mathrm{ARD}}$} & WS & 1.6 & $1.1-3.5$ & 0.02 & 5.4 & $1.7-14.9$ & 0.01 \\
\hline & CS & 1.4 & $0.4-1.7$ & 0.35 & 5.4 & $5.0-14.0$ & 0.0005 \\
\hline \multirow{2}{*}{$\begin{array}{l}\text { ARD only } \\
(n=3)\end{array}$} & WS & 3.0 & $1.4-4.6$ & 0.02 & 11.4 & $3.6-24.1$ & 0.02 \\
\hline & CS & 1.6 & $0.6-1.7$ & 0.14 & 11.2 & $4.1-22.0$ & 0.006 \\
\hline
\end{tabular}

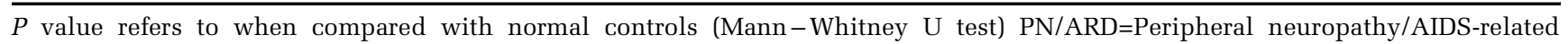
dementia 
groups were matched for CD4 count. No significant difference was detected between the two groups.

We were unable to demonstrate any effect of sex, age or BMI on thermosensory threshold abnormalities ( $P>0.05$ for all factors).

\section{Discussion}

Several factors affect the results of thermosensory testing, including the anatomical site tested, method of measurement and intra- or intersubject variability. The constant stimuli methods used exclude reaction time artefact and are more sensitive (Claus et al, 1990; Yarnitsky and Ochoa, 1990) and less dependent on the patient's concentration. The feet are more likely to be involved in early PN than the hands. The dorsum of the foot and the anterior aspect of the forearm were chosen because of ease of applying the thermode to a fairly flat surface. In order to minimise intersubject variability, all tests were performed by one investigator. The reported intra-subject variability for thermosensory tests in the literature depends on the methodology used, and can vary between $5 \%$ (Janel et al, 1985) and $150 \%$ (Fagius and Wahren, 1981). The CV of mean of our study range between $24-33 \%$ for the foot, and $21-24 \%$ for the forearm.

To our knowledge, thermosensory thresholds in HIV infected patients have been studied by three other groups (Winer et al, 1992; Berger et al, 1993; Smith et al, 1990). Winer et al (1992) found the upper limits of the temperature threshold of the foot to be lower than in our study (e.g. warm sensation up to $1.0^{\circ} \mathrm{C}$ for normal controls and $8.0^{\circ} \mathrm{C}$ for those with neuropathy), which may reflect differences in methodology, since the thermode was placed on the plantar rather than the dorsal surfaces of the feet (Fowler et al, 1987), thermal properties of the skin show marked variation between sites (Stevens et al, 1974). Winer et al (1992) also preceded their tests by establishing an approximate value for the threshold before fine tuning the measurements, a step which we have omitted. Since patients demonstrate a learning process in thermosensory testing (Jamal et al, 1985), this may contribute to the differences observed. Most importantly, their study may have used a different computer algorithm to that of TSA 2001 (Thermo Sensory Analyser from Medoc $L t d$ ). Normative data obtained usind identical equipment showed a very similar upper limit of normal value to ourselves (Yarnitsky and Sprecher, 1994).

All patients in our study with clinical PN showed WS and/or CS thresholds of the lower limbs above the 95th centile for controls, though the number of patients involved were small. One patient who had symptoms referable to the upper limb also had abnormal thresholds of the forearm. Furthermore, the median WS and CS of both sites were significantly different from the controls and asymptomatic HIV positive patients. It may therefore be argued that the diagnosis of peripheral neuropathy should be questioned if a patient has no detectable thermosensory abnormalities especially of the foot, and this confirms the results from previous studies (Winer et al, 1992; Berger et al, 1993) which found quantitative sensory testing to be a sensitive laboratory measure of neuropathy.

However, thermosensory abnormalities are not limited to those with clinical evidence of neuropathy since patients who experience their first AIDS defining illness without clinical PN were also found to have significantly higher median WS thresholds of both sites compared to controls. Even patients in the asymptomatic stage of HIV disease had significantly abnormal thresholds. There is also a trend towards higher median CS with increasing severity of HIV disease, though not reaching statistical significance for those without clinincal PN. This may be because sensation for cold is transmitted through larger, thinly-myelinated $\mathrm{A} \delta$ fibres, rather than the unmyelinated $\mathrm{C}$ fibres responsible for warm sensation (Light and Perl, 1984), and may therefore be affected later in the disease process. These findings confirm those of previous study where Winer et al also found abnormal thresholds in three of 10 patients without neuropathic symptoms or signs and in some patients without AIDS and AIDS-related complex (Winer et al, 1992).

We wer not able to consistently demonstrate a relationship between thermosensory thresholds and CD4 counts due to the small sample size of the study.

At the moment we can only postulate on the significance of these findings. It is plausible that the processes causing clinical PN in HIV disease may occur very early, even in the asymptomatic stage. Electrophysiologic studies of patients without clinical PN showed primarily lower limb nerve conduction velocity abnormalities in symptomatic (CDC group IV) HIV positive patients when compared to seronegative controls (Smith et al, 1990; Fuller et al, 1991; Ronchi et al, 1992), and a recent study showed significantly lower sural nerve conduction velocities even in asymptomatic HIV patients with normal CD4 counts (Malessa et al, 1996). Evoked potentials in HIV patients without neurological symptoms have also been studied. Auditory P300 latency was delayed in up to $30 \%$ of these patients (Birdsall et al, 1994); sensory evoked potential was abnormal in up to $10 \%$, and some of them went on to develop clinical PN (Jabbari et al, 1993). Quantitative sensory testing such as thermosensory thresholds may also be a useful, non-invasive test to detect early, small fibre damage before clinically obvious peripheral neuropathy. We are undertaking a long term prospective study to evaluate the natural history and predictive 


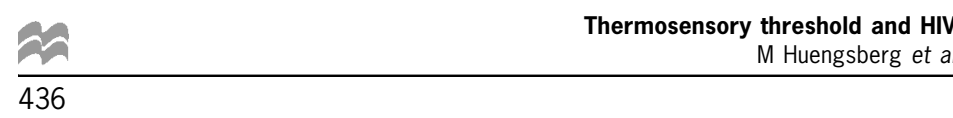

value of abnormal thermosensory thresholds in the subsequent development of HIV related neuropathy.

This study could not confirm or refute a relationship between taking known neurotoxic antiretroviral drugs such as ddI or $\mathrm{ddC}$ and changes in thermosensory thresholds, although a longer follow-up period and larger cohort may demonstrate such an effect. An early predictor of peripheral neuropathy would be an invaluable tool in the management of drug related neural toxicity in HIV infected patients.

\section{Materials and methods}

Equipment

A Thermo Sensory Analyser (TSA 2001: from Medoc Ltd) was used to measure the threshold for warm sensation (WS) and cold sensation (CS). A small thermode was attached to the patient and capable of heating and cooling the skin from the predetermined baseline temperature of $32^{\circ} \mathrm{C}$. The method chosen for this study is one of 'Constant Stimuli Methods' called the 'Staircase Test' (Claus et al, 1990), where the thermode temperature was increased or decreased automatically according to the subject's response. The Thermode was placed on the dorsum of the right foot and anterior aspect of the right wrist in all cases.

\section{Subjects}

Patients with diabetes, vitamin B12 deficiency or family history of neuropathy were excluded from the study. Patients whose alcohol intake was greater than 40 units per week (one unit of alcohol is equivalent to one glass of wine, half pint of beer or one shot of spirit) or on neurotoxic drugs other than antiretroviral therapy were also excluded.

Informed consent was obtained from the controls and patients and the study was approved by the local ethical committee.

Patients were all HIV antibody positive and recruited from two dedicated outpatient clinics in Birmingham (The General Hospital and Heartland's Hospital), UK, between May 1993 and December 1995. Seventy-five patients were recruited comprising three women and 72 men; 65 were men who had sex with men, six came from sub-Saharan Africa and four acquired HIV infection heterosexually. There were no injecting drug users in this cohort. The median age was 35

\section{References}

Bacellar H, Munoz A, Miller EN, Cohen BA, Besley D, Selnes OA, Becker JT, McArthur JC (1994). Temporal trends in the incidence of HIV-1-related neurologic diseases: Multicenter AIDS Cohort Study, 1985-1992. Neurology 44: 1892-1900. (inter-quartile range 29-43).

All patients were questioned about neurological symptoms and received a standardised neurological examination. Standardised neurological symptom and disability scores (Dyck et al, 1980; Winer et al, 1992) were used and patients who scored more than two on the symptom score and more than six on the disability score were considered abnormal and defined as having clinical peripheral neuropathy. Abbreviated Neuropsychiatric AIDS Rating Scale (NARS) devised by Price and Brew (1988) was used and patients scored $\geqslant 1$ was considered to have dementia. Thermosensory tests were performed in all patients and the diagnosis of clinical peripheral neuropathy was made without the results of thermosensory tests. CD4 lymphocyte counts were performed within 30 days of thermosensory measurements.

In order to assess the effect of didanosine (ddI) or zalcitabine (ddC), thermosensory thresholds were compared between patients who took ddI and/or $\mathrm{ddC}$ and those who did not, after matching for CD4 counts.

Data on age was available in all patients, and data on Body Mass Index (BMI) in 56 of the 75 patients.

\section{Controls}

Controls were recruited from presumed HIV negative staff and male patients who attended the GU clinic for unrelated conditions and had a negative HIV antibody test. Subjects with past or present history of neurological diseases were excluded. Forty controls were recruited comprising 33 heterosexual males, three homosexual males (both HIV negative) and four females. The median age was 33.5 (inter-quartile range $28-45$ ).

\section{Co-efficient of variability (CV) of the mean}

Data from five controls and 15 patients who had a repeat test at the same session were used to measure $\mathrm{CV}$ of the mean of the thermosensory test. All tests were performed by one investigator $(\mathrm{MH})$.

\section{Statistics}

Computer software package Minitab version 11 was used for statistical analysis. Mann - Whitney U test was used for non-parametric comparison of two groups; stepwise multiple regression was used to assess the effects of sex, age and BMI on themosensory thresholds; $P$ value of $<0.05$ was considered significant.

Berger AR, Arezzo JC, Schaumburg HH, Skowron G, Merigan T, Bozzette S, Richman D, Soo W (1993). 2',3'-dideoxycytidine (ddC) toxic neuropathy: a study of 52 patients. Neurology 43: 358-362. 
Birdsall HH, Ozluoglu LN, Lew HL, Trial J, Brown DP, Wofford MJ, Jerger JF, Rossen RD (1994). Auditory P300 abnormalities and leukocyte activation in HIV infection. Otolaryngology - Head \& Neck Surgery 110: $53-59$.

Brown MJ, Martin JAR, Asbury AK (1976). Painful diabetic neuropathy - a morphometric study. Archives of Neurology 33: 164.

Brown MJ, Asbury AK (1984). Diabetic neuropathy. Annals of Neurology 15: 2-12.

Claus D, Hilz MJ, Neundorfer B (1990). Thermal discrimination thresholds: a comparison of different methods. Acta Neurologica Scandinavica 81: 533540.

Claus D, Mustafa C, Vogel W, Herz M, Neundorfer B (1993). Assessment of diabetic neuropathy: definition of norm and discrimination of abnormal nerve function. Muscle \& Nerve 16: 757-768.

Dalakas MC, Pezeshkpour GH (1988). Neuromuscular diseases associated with human immunodeficiency virus infection. [Review] [42 refs]. Annals of Neurology 23 (Suppl), S38-48.

de la Monte SM, Gabuzda DH, Ho DD, Brown Jr RH, Hedley-Whyte ET, Schooley RT, Hirsch MS, Bhan AK (1988). Peripheral neuropathy in the acquired immunodeficiency syndrome. Annals of Neurology 23: $485-492$.

Dyck PJ, Sherman WR, Hallcher LM, et al. (1980) Human diabetic endoneurial sorbitol, fructose and myoinositol related to sural nerve morphometry. Annals of Neurology 8: $590-596$.

Dyck PJ, Karnes J, O’Brien PC, Zimmerman IR (1984). Detection thresholds of cutaneous sensation in humans. In Peripheral Neuropathy. Dyck PJ, Thomas PK, Lambert EH, Bunge R, (eds). Saunders: Philadelphia: pp. $1103-1138$.

Fagius J, Wahren LK (1981). Variability of sensory threshold determination in clinical use. Journal of Neuroscience 51: 11-27.

Fowler CJ, Carroll MB, Burns D, Howe N, Robinson K (1987). A portable system for measuring cutaneous thresholds for warming and cooling. Journal of Neurology, Neurosurgery \& Psychiatry 50: 1211-1215.

Fruhstorfer H, Lindblom U, Schnidt WG. (1976). Method for quantitative estimation of thermal thresholds in patients. Journal of Neurology, Neurosurgery \& Psychiatry 39: $1071-1075$.

Fuller GN, Jacobs JM, Guiloff RJ (1990). Axonal atrophy in the painful peripheral neuropathy in AIDS. Acta Neuropathologica 81: 198-203.

Fullre GN, Jacobs JM, Guiloff RJ (1991). Subclinical peripheral nerve involvement in AIDS: an electrophysiological and pathological study. Journal of Neurology, Neurosurgery \& Psychiatry 54: 318-324.

Fuller GN, Jacobs JM, Guiloff RJ (1993). Nature and incidence of peripheral nerve syndromes in HIV infection. Journal of Neurology, Neurosurgery $\&$ Psychiatry 56: $372-381$.
Jabbari B, Coats M, Salazar A, Martin A, Scherokman B, Laws WA (1993). Longitudinal study of EEG and evoked potentials in neurologically asymptomatic HIV infected subjects. Electroencephalography \& Clinical Neurophysiology, 86: 145-151.

Jamal GA, Weir AI, Hansen S, Ballantyne JP (1985). An improved automated method for the measurement of thermal thresholds. 2. Patients with peripheral neuropathy. Journal of Neurology, Neurosurgery \& Psychiatry 48: $361-366$.

Light AR, Perl ER (1984). Peripheral sensory systems, In Peripheral Neuropathy, Dyck PJ, Thomas PK, Lambert EH, Bunge R (eds). Saunders: Philadelphia. pp 310330.

Malessa R, Agelink M, Himmelmann M, Kloss T, Mertins L, Brockmeyer NH (1996). Nerve conduction changes in asymptomatic HIV-1 seropositive individuals in the absence of other risk factors for neuropathy. Electromyography \& Clinical Neurophysiology 36: 3-8.

Navarro X, Kennedy WR (1991). Evaluation of thermal and pain sensitivity in type I diabetic patients. Journal of Neurology, Neurosurgery \& Psychiatry 54: 60-64.

Price RW, Brew BJ (1988). The AIDS Dementia Complex. Journal of Infectious Diseases 158: 1079-1083.

Ronchi O, Grippo A, Ghidini P, Lolli F, Lorenzo M, Di Pietro M, Mazzotta F (1992). Electrophysiologic study of HIV-1 + patients without signs of peripheral neuropathy. Journal of the Neurological Sciences 113, 209-213.

Said G, Slama G, Selva J (1983). Progressive centripetal degeneration of axons in small fibre diabetic polyneuropathy: a clinical and pathological study. Brain 106: $791-807$.

Smith T, Jakobsen J, Gaub J, Trojaborg W (1990). Symptomatic polyneuropathy in human immunodeficiency virus antibody seropositive men with and without immune deficiency: a comparative electrophysiological study. Journal of Neurology, Neurosurgery \& Psychiatry 53: 1056-1059.

Stevens JC, Lawrence EM, Simonson DC (1974). Regional sensitivity and spatial summation in the warmth sense. Physiology \& Behavior 13: $825-832$.

Winer JB, Bang B, Clarke JR, Knox K, Cook TJ, Gompels M, Hughes RA, Hall SM, Pinching AJ, Harris JW, et al. (1992). A study of neuropathy in HIV infection. Quarterly Journal of Medicine 83: 473-488.

Yarnitsky D, Ochoa JL (1990). Studies of heat pain sensation in man: perception thresholds, rate of stimulus rise and reaction time. Pain 40: 85-91.

Yarnitsky D, Sprecher E (1994). Thermal testing: normative data and repeatability for various test algorithms. Journal of Neurological Sciences 125: 39-45. 